\title{
Rodrigo Arroyo Castro \\ Incomunicaciones
}

Valparaíso: Ediciones Inubicalistas, 2013.

\section{INCOMUNICACIONES}

\section{Por Julieta Marchant Universidad Diego Portales julieta.marchant.rivera@gmail.com}

Escribir y ser escrito. Leer y ser leído. El que escribe también es escrito cuando, empujando la mano sobre el papel, se enfrenta a la fragilidad de un lenguaje que porta el deseo de esa mano. La mano tiembla y teme. La mano, esta mano, piensa un modo de escribir en una lejanía, en una opacidad, fuera de la intención violenta de la captura y de la representación: "La escritura es posible como un modo de estar lejos" (Arroyo) ${ }^{1}$. Asistimos, en la escritura de Rodrigo Arroyo (Curicó, 1981), a la apertura del poema, a esa hospitalidad que Derrida ve en la literatura y que no es más que no negar el porvenir, dejar ingresar al otro al lenguaje que, de antemano fracturado, vamos tejiendo lentamente a través de las palabras y que el otro que leerá, que recibirá esa escritura, pueda firmarlo en ese recibimiento ${ }^{2}$. No somos soberanos del lenguaje, parece decirnos esta poesía. Nada de él nos pertenece y, sin embargo, las palabras aparecen, como pequeñas lámparas, velando la experiencia de escribir. Aparecen, fulguran y se apagan y vuelven a llamarnos cuando faltan.

1 Este libro no tiene numeración de páginas, por lo que al citarlo indicaremos solamente el apellido del autor.

2 Dice Derrida en El gusto del secreto: "Dar a leer al otro significa también dejar desear, o dejar al otro el lugar de una intervención con la cual podrá escribir su interpretación: el otro deberá poder firmar mi texto" (47). Se trata más que nada de una política de la "hospitalidad para la lectura del otro" (48). 
En El sentido del mundo, nos dice Jean-Luc Nancy que "lo que no responde a un modelo, sea el que fuera, de apropiación de la significación, lo que abre la relación y, con ella, la significancia, es lo que nosotros llamamos la escritura" (175). La escritura, entonces, sería "lo que precede a la significación, lo que la sucede y la excede" y el sentido "que resulte posible algo así como la transmisión de un 'mensaje.. Es la relación en cuanto tal y ninguna otra cosa" (175). Algo nos conmueve de la escritura de Rodrigo Arroyo cada vez que leemos este libro, más allá de todo pensamiento, más allá de toda idea que pudiéramos o deseáramos conferirle a esta poesía, más allá de todo deseo que nos arrastre a intentar "traducirla" o descifrarla - es decir, reducirla a un par de nociones o supuestos- más allá de todo gesto racional de un lector que pretendiera encontrar un significado en esto que hoy leemos y que nos estremece en su venida. Eso que nos conmueve quizá, y que pareciera siempre ubicarse en un más allá de la significación o la captura, es la interpelación que en ella habita, lo que de ella nos llama, cuando la escritura no cesa de venir y, así, nos reúne, nos convoca, esto es, siguiendo a Nancy, sucede en y por la relación. "Apertura a cada instante de este mundo-aquî" (177), dirá Nancy; en el instante de la escritura, en ese momento singular, presente como chispazo y también como espera -o sea, como ausencia- ocurre la poesía. Y este mundo-aquí, que se nos abre en Incomunicaciones de Rodrigo Arroyo, sucede, justamente, en la apertura hacia lo otro. Cómo describir, entonces, este libro, cómo reseñarlo y cómo incluso verlo solamente así -como un libro- cuando la invitación parece ser lo contrario: no leerlo como un libro, en tanto la idea de libro tradicional apela a algo cerrado, concluso, posible de capturar por una materialidad ${ }^{3}$-las hojas, el hilo, la cartulina, ideas que tanto han preocupado también al autor, a este autor que nunca ha dejado de pensar en el libro como materia sujeta a ciertas disposiciones que lo atrapan y sofocan-.

Cómo escribir, al fin, sobre Incomunicaciones -esa idea realmente me inquieta-cuando uno quisiera disponerse a leer y a ser leído por Incomunicaciones, esto es, cuando en esta escritura, pensamos nuevamente con Nancy, lo que acontece es el sentido en la relación. El sentido del mundo, de alguien que atestigua su existencia en el mundo (Nancy 117), su pequeña y particular existencia junto a otros mundos también particulares y múltiples. He aquí la escritura como gesto político por esencia, pues en esa relación que ocurre en la escritura y que le da sentido, y no por ello significado, lo que sucede ante todo, dirá Nancy, es "la resistencia infinita del sentido en la configuración del 'conjunto"' (176). Y podríamos tal vez pensar que de eso proviene nuestra conmoción: esta escritura, mientras nos llama, escribe sobre la herida y desde la herida - a través de ella-, en un gesto político que nada tiene que ver con

3 Escribe Derrida en "Edmond Jabès y la cuestión del libro": [E]l libro no está terminado nunca. Queda siempre en suspenso y a media luz” (103), lo que podríamos vincular a la hospitalidad de la que hablamos más arriba, en cuanto toda escritura sucede abierta al porvenir, inclausurable, en el juego y desplazamiento de significaciones que la multiplican al infinito y que, por ello, está suspendida, a media luz, aunque la materialidad que la contiene intente indicar un cierto límite, una finitud. 
causas o compromisos, en el sentido panfletario. Tal vez por ello se pregunta: “ $i[Q]$ ué estallido se consigue ignorando los panfletos?” (Arroyo). Aparece así, y ya al final de Incomunicaciones, la imagen indescriptible de Luchín, el estallido de un puñado de palabras que llegan siempre para hablar del dolor: "No puede haber palabra que no diga del dolor" (Arroyo), "[l]as palabras que Luchín deja en el suelo son parte / de un idioma que es pura grieta y fisura en sus cimientos, / un silencio que nos ata" (Arroyo). Llega Luchín a este libro y su figura nos habla de la catástrofe - "en tiempos sombríos como estos" (Arroyo) -, de nuestros muertos, sabiendo que "la paradoja de la ausencia es la presencia de un ocaso" (Arroyo), porque en este lenguaje siempre prestado, porque en esta escritura que aloja lo político, nuestros muertos se presentan del único modo posible: ausentándose, en el pálpito de una falta o carencia que nos remece. "Un poema es la única forma de estar viniendo y no" (Arroyo), escribe Rodrigo, es decir, el poema siempre está por venir, es una espera - primera condición de la falta-, de esa ausencia que es presencia de un ocaso o de esa ausencia de un ocaso que se nos presenta como falta y que no deja de interpelarnos. Quién ha dicho que los que estamos presentes somos los vivos, los que acarreamos con un cuerpo tibio. Quién ha dicho, quién ha osado instalar la verdad de que nosotros, los vivos, somos lo presente y que nuestros muertos son incapaces de presentarse. Un segundo asunto entonces -y sumado a la escritura como sentido en la relación- es la cuestión de la presencia.

"Todo se construye basado en las distancias / en la ausencia de sentido / en la belleza de los gestos nada más" (Arroyo), leemos en Incomunicaciones. La belleza en los gestos de Luchín, mientras lo soñamos sin quemaduras. La ausencia de sentido que abandona su posible negatividad, en la medida en que edificamos desde otro lugar, desde la belleza de los gestos, desde acercarse al otro para acariciar un rostro herido, desde la jornada con un viejo compañero, desde el llamado que este libro nos hace sin intención ni objetivo, sin pretensión de trascendencia, a comenzar una conversación. Es como si nos dijera: la poesía ocurre en otra parte, la poesía ni siquiera ocurre en el lenguaje, mucho menos mediante él - “decir poema es quizá una paulatina desaparición de las palabras" (Arroyo)-, sino que ocurre en la experiencia, en ese "estar fuera de lugar, / suspendido" (Arroyo). A lo mejor por eso nos dice: "Escribir es mirarnos a los ojos" (Arroyo), mirar al otro a los ojos, que nos devuelve en el reflejo, en el silencio, en el breve instante del encuentro.

En ese sentido, en Incomunicaciones asistimos a la apelación directa, textual, clara incluso, hacia el otro; gesto que registramos en una segunda persona insistente, que no cesa de "presentarse" cada vez que es llamada por esta voz, y que vemos sobre todo en las primeras partes del libro: compañía y ausencia de alguien que el yo llama, en el deseo de aplacar la soledad o en la necesidad de contacto. Se trata nuevamente de la falta, pues, tal como se sabe de la derrota frente al lenguaje, este yo, aunque parece creer que todo sucede en el encuentro con el rostro del otro, se lamenta escribiendo ante la certeza de la ilusión: "Darle cabida a la ilusión de hablarle a un otro" (Arroyo). Si este otro se presenta es -como los muertos- en su ausencia. Si el yo lo llama, es 
porque no está; si el yo lo desea, es porque le falta y, en esa carencia, es huellado. Así, ese otro -que deambula entre un otro amoroso, un otro que es el mismo yo interpelándose y multiplicándose y, en ocasiones, un otro como compañero de ruta- signa una primera falta al principio del libro que no dejará de acontecer hasta el final y que nos habla, sin duda, de una poética aquejada por la ausencia. Sin embargo, a pesar de aquello, hay momentos en el libro sumamente conmovedores donde el contacto es posible. La experiencia del contacto ocurre de un modo inaudito, casi insólito, a tal punto que ya no sabemos quién es el que busca y quién es el buscado, quién es el que escribe y quién es el escrito: "Y lloras o lloro, no lo sé. Despierto o despiertas y soy o eres una mano empujando un lápiz sobre el papel" (Arroyo). Lloras o lloro, despierto o despiertas y soy o eres. Esa "o" que, aunque distancia una palabra de otra, señala, a su vez, el lugar impreciso del alcance: soy o eres una mano empujando un lápiz sobre el papel. El yo se disuelve, se entrega, se ofrenda a este otro y este otro hace lo propio, hasta que esa "o" nos envuelve en el preciso instante en que el encuentro es posible y ya no podríamos diferenciar quién es el uno y quién es el otro. Ese instante tan pleno y tan luminoso de amar antes de saberse amado, una de las condiciones que enuncia Derrida para que la amistad sea posible, es decir, de amar no para ser amado, sin objetivo alguno y concernido por ese acontecimiento ${ }^{4}$.

Sin adentro y sin afuera se desean el yo y ese otro, "sin afuera y sin adentro, moviéndonos junto a una veleta, escapándonos de los límites de la representación” (Arroyo). Otro asunto aquí, de este modo -y unido al de la presencia- es la representación, representada, a su vez, en Incomunicaciones, a través la imagen del video que, como telón de fondo, nos recuerda, entre otras cosas, una de las condiciones de cierto arte y de cierto lenguaje que parece limitarse y desfallecer en la representación: "[U]n video es siempre el movimiento de una imagen plana, bidimensional, ajena a la lluvia" (Arroyo), pues "[t] oda representación suprime un duelo ausente" (Arroyo). Ante las categorías de la representación, ante la medición que toda representación hace de los objetos, este libro duda. De esta forma, paulatinamente vemos desbordadas las distancias entre quien representa o mide y entre lo representado o medido: "[U]n grabado puede reproducirse tantas veces / que la imagen se apropia de las líneas que los ojos dibujan cuando miran” (Arroyo) o "una pintura / no es más que un objeto en posición horizontal / un cuerpo que permanece ahí, palpándonos la mirada" (Arroyo). ¿Nosotros miramos a la pintura o ella nos mira a nosotros, nos palpa la mirada?, ¿nosotros miramos un grabado o él dibuja las líneas que nuestra mirada traza? Y, finalmente, ¿escribe el que escribe o bien escribe el que es escrito?, ¿no será acaso el momento en el que las palabras nos buscan y van a nuestro encuentro cuando escribimos? Pienso esto desde la oposición, siempre previa a la conciencia o a

4 Dice Derrida en Políticas de la amistad: "La amistad, el ser-amigo, pues, ¿qué es? Pues bien, amar antes de ser amado. Antes incluso de pensar lo que quiere decir amar, el amor, la amancia (...). El amigo es aquel que ama antes de ser aquel al que se ama" (25-26). 
la intención de oposición, de escribir por algo o para alguien, es decir, de escribir para representar, para hacer que algo aparezca. Cuando, en realidad, si acá algo "aparece" es simplemente el relampagueo de una falta, de un cuerpo que no ha cesado de morar en la ausencia y de una mano que, aun escribiendo, sabe que empujar su carne por el papel es un gesto de extravío. Así, nos preguntamos quién mira y quién es mirado, quién escribe y es escrito, mientras asistimos a esta escritura que es la búsqueda del otro ni adentro ni afuera, en un trayecto que no está sujeto ni a la representación ni a los videos y que, encontrando y no el lugar del encuentro, se pregunta: “¿Es la esquina del lenguaje una guarida?" (Arroyo).

"La mano que escribe es aquella que agita el velamen / en medio del naufragio" (Arroyo), leemos en Incomunicaciones. El velamen, o sea, el conjunto de velas de una embarcación, aquí en extravío y naufragio. Velamen de vela que, a su vez, es el plural del latín velum, lienzo, tela. ¿Qué será, entonces, agitar el velamen?, ¿qué podríamos intuir cuando pensamos que escribir es agitar el velamen? En un primer momento, aparece como el gesto ante el fracaso que toda escritura contiene -agitar velas cuando se naufraga en el lenguaje y nos extraviamos-, pero, en tanto velamen está unido a la palabra velo, signa también el acto de enarbolar el velo, no sacarlo del todo, pero sí mecerlo y, en ese movimiento, dejar que el rostro del otro -antes cubierto del todo por el velo- aparezca. Imaginamos la imagen del rostro de alguien que aparece cuando el viento lo descubre y que luego desaparece y vuelve a aparecer, siempre distinto y singular en cada venida. Así son también estos poemas, que en esa agitación del velo no cesan de llegar al tiempo que se ausentan, mientras esa mano que teme y tiembla y que, sin embargo, escribe, agita el velamen en medio del naufragio.

\section{Referencias}

Derrida, Jacques. "Edmond Jabès y la cuestión del libro". La escritura y la diferencia. Trad. Patricio Peñalver. Barcelona: Anthropos, 1989. 90-106. Medio impreso. ---. Políticas de la amistad. Trad. Patricio Peñalver y Francisco Vidarte. Madrid: Trotta, 1998. Medio impreso.

Derrida, Jacques y Maurizio Ferraris. El gusto del secreto. Trad. Luciano Padilla López. Buenos Aires: Amorrortu, 2009. Medio impreso.

Nancy, Jean-Luc. El sentido del mundo. Trad. Jorge Manuel Casas. Buenos Aires: La Marca, 2003. Medio impreso. 